\title{
Are lead-free piezoelectrics more environmentally friendly?
}

T. Ibn-Mohammed, and S. C. L. Koh, Centre for Energy, Environment and Sustainability, The University of Sheffield, Sheffield S10 1FL, UK; Advanced Resource Efficiency Centre, The University of Sheffield, Sheffield S10 1FL, UK

I. M. Reaney, and D. C. Sinclair, Departments of Materials Science and Engineering, The University of Sheffield, Sheffield S1 3JD, UK

K. B. Mustapha, Departments of Mechanical, Materials and Manufacturing Engineering, University of Nottingham, Malaysia Campus, Selangor Darul Ehsan 43500, Malaysia

A. Acquaye, Kent Business School, University of Kent, Canterbury CT2 7PE, UK

D. Wang, Departments of Materials Science and Engineering, The University of Sheffield, Sheffield S1 3JD, UK

Address all correspondence to T. Ibn-Mohammed, I. M. Reaney at t.ibn-mohammed@sheffield.ac.uk; i.m.reaney@sheffield.ac.uk

(Received 16 December 2016; accepted 30 January 2017)

\begin{abstract}
Considered as a less hazardous piezoelectric material, potassium sodium niobate (KNN) has been in the fore of the search for replacement of lead $(\mathrm{Pb})$ zirconate titanate for piezoelectrics applications. Here, we challenge the environmental credentials of KNN due to the presence of $\sim 60 \mathrm{wt} \% \mathrm{Nb}_{2} \mathrm{O}_{5}$, a substance much less toxic to humans than $\mathrm{Pb}$ oxide, but whose mining and extraction cause significant environmental damage.
\end{abstract}

Piezoelectric materials based on lead zirconate titanate, $\mathrm{PbZr}_{x} \mathrm{Ti}_{1-x} \mathrm{O}_{3}$, (PZT) have held sway in numerous applications (automobiles, microphones, sonar, resonators, medical imaging/diagnostics, printers, ultrasonic motors, wearable devices, smart structures, medical implants, etc.) for over 50 years. The dominance of PZT-based ceramics is due to their superior piezoelectric response, which ultimately ensures an unmatched efficiency in the direct interconversion of electrical and mechanical energy. Beyond this superior piezoelectric response, lies a level of toxicity that threatens the position of PZT as the leading piezoelectric ceramic, and has sparked urgent global efforts to identify environmentally benign substitutes. PZT accrues its toxicity from $>60 \mathrm{wt} \%$ lead oxide $(\mathrm{PbO})$. $\mathrm{Pb}$ is a toxic heavy metal that has been the subject of calls for elimination from all consumer electronics and products, ${ }^{[1-6]}$ based on worldwide initiatives for electronic equipment reuse and recycling such as the EU directives on waste electrical and electronic equipment (WEEE) and restriction of hazardous substances (RoHS). ${ }^{[3,7,8]}$

A fundamental issue that emerges with the recognition of PZT's toxicity is the need to find surrogate materials (with improved eco-friendliness and excellent piezo-activity) in the myriad of products in which PZT plays a major functional role. Potassium sodium niobate $\left(\mathrm{K}_{x} \mathrm{Na}_{1-x} \mathrm{NbO}_{3}\right.$ or KNN hereafter) is a potential $\mathrm{Pb}$-free replacement for $\mathrm{PZT}^{[4]}$ and for room temperature applications in particular looks promising. Material replacement in existing products has many obstacles, such as substitution costs, price ratio, and in some instance the end user's propensity to change. ${ }^{[9]}$ Consequently, for material substitution to be viable: (i) the benefit of implementing a novel and untested material must be worth the risk of abandoning the well-established current materials; (ii) the cost of substitution must not exceed the overall benefits; (iii) the costs of renovating production equipment and processes is acceptable; (iv) the implications of substitution are manageable in a wider systems context; and (v) institutional, legal, social, and environmental consequences can be overcome. Aimed at addressing this techno-economic challenge for $\mathrm{KNN}$ versus PZT, the latest findings by Ibn-Mohammed et al., ${ }^{[10]}$ published by the Royal Society of Chemistry in the "Energy and Environmental Science" Journal, illustrate the danger of hasty assumptions about "green" credentials by considering only usephase toxicity.

The piezoelectric effect was first demonstrated in the seminal work of the Curie brothers ${ }^{[1]]}$ in crystals such as quartz, Rochelle salt, and tourmaline, which were shown to convert mechanical to electrical energy and vice versa, giving rise to sensing and actuating applications. ${ }^{[12]}$ A string of ground breaking research advances have subsequently been reported, encompassing synthetic polycrystalline ceramics, single crystals, and thick/thin films, and resulting in a year on year increase in piezoelectric applications. ${ }^{[13]} \mathrm{A}$ recent study estimated the global market for piezoelectric actuators alone to be nearly US\$7 billion, with a growth rate of $13 \%$ per annum. ${ }^{[14]}$ 


\section{The race to replace PZT with KNN}

The case for the replacement of PZT in many products has peaked in recent time due to the increasing awareness of environmental and health issues related to the presence of $>60 \mathrm{wt} \%$ $\mathrm{PbO}^{[3,15]}$ The widespread usage of PZT for everyday items means $\mathrm{PbO}$ is released into the atmosphere during the life cycle of these products. The emission of $\mathrm{PbO}$ from PZT-based products can be by evaporation from the starting oxides during calcination and sintering in the production phase or through machining or improper waste disposal. Accordingly, the need to protect the environment from pollution and safeguard human health against $\mathrm{Pb}$ toxicity forms the bedrock of WEEE and RoHS legislation, which relates to PZT.

Without the veiled threat of removing current exemptions from $\mathrm{PZT}$, which permit the use of $\mathrm{PbO}$, it is highly unlikely that anywhere near the volume of research published to date on PbO-free ceramics would have been undertaken. Nonetheless, the threat of removing exemptions has resulted in noticeable progress with the development of promising $\mathrm{Pb}$-free piezoelectric materials, which are broadly speaking based around $\mathrm{Nb}_{2} \mathrm{O}_{5}$ and $\mathrm{Bi}_{2} \mathrm{O}_{3}$ containing complex oxides. ${ }^{[15-21]}$ These materials however, suffer from: a weaker piezoelectric response ${ }^{[16]}$; costly fabrication techniques with questionable scalability ${ }^{[17,18]}$; challenges with domain control as a result of inappropriate crystal symmetry ${ }^{[19]}$ and high volatility, hence difficulty in maintaining stoichiometry. ${ }^{[20]}$ Notwithstanding the technical challenges highlighted above, among all the $\mathrm{Pb}$-free candidates, potassium sodium niobate (or KNN-based compositions) has become one of the most widely researched $\mathrm{Pb}$-free piezoelectric materials since the landmark paper by Saito et al. ${ }^{[4]}$ Recent advances are described in detail in Refs. 14, 21.

Although not as performant as PZT, KNN is amenable to doping to improve its piezoelectric performance, compatible with low cost nickel internal electrodes for multilayering ${ }^{[21]}$ and endowed with a high Curie temperature $\left(T_{\mathrm{C}}>400^{\circ} \mathrm{C}\right)$, making ceramics difficult to depole $e^{[1,3,22,23]}$ during operation. These factors have led to many academic research groups touting KNN-based ceramics as the most likely to succeed in substituting PZT in applications, should exemptions to WEEE and RoHS for piezoelectric ceramics be revoked. ${ }^{[4,15,22,24]}$ However, before exploitation can be contemplated, a critical assessment of all aspects of KNN-based technology must be undertaken. New Pb-free materials must offer not only technical parity to their traditional counterparts, but also a superior environmental and social footprint. A newly published study by Ibn-Mohammed et al. ${ }^{[10]}$ challenges the latter and re-evaluates the assumption that KNN is intrinsically "greener" than PZT.

Employing a quantitative framework of hybrid life cycle analysis (LCA), the study provides a comprehensive cradle-to-grave environmental impact of KNN versus PZT within a holistic process-design framework. LCA is a wellestablished computational tool with which to evaluate the complete environmental impact of a material or product from the raw materials extraction, through processing to the use phases, and finally to disposal. ${ }^{[25]}$ It is an important tool in the lowcarbon economy where all the highlighted phases of consumer goods have consequential global environmental impact. ${ }^{[26,27]}$

As will be further explored in the following paragraphs, the research reported by Ibn-Mohammed et al. ${ }^{[10]}$ facilitates effective environmental decision making for the many stakeholders (consumers, policy makers, industrialists, environmentalists, etc.) in the substitution of PZT by KNN and demonstrates potential new environmental problems. Although there are questions regarding the overall toxicity and environmental impacts of piezoelectric functional materials, there are a number of other unknown factors, including mass production yield, reliability, and economies of scale that must be considered regarding alternative lower performing $\mathrm{Pb}$-free systems such as KNN. Nevertheless, it is highly unlikely that such variations will have any significant effect during scale up of the materials. In fact, even if the manufacturing route of KNN becomes well-established at the industrial scale, the cost of substitution and energy consumption will still be relatively higher than for PZT, provided properties, including specific heat capacity, Curie temperature, and other thermodynamic properties remain the same. ${ }^{[10]}$ At the moment, none of the piezoelectric material alternatives are drop-in substitutes for PZT due to electromechanical properties (e.g., device design), electrical properties (e.g., electronic drivers and amplifiers) as well as cost of redesign and approvals. ${ }^{[10]}$

\section{Comparison of environmental profile of PZT versus KNN piezoelectric material}

Figure 1 shows the comparison of the environmental profile of PZT versus KNN across a number of environmental indicators namely: primary energy consumption [Fig. 1(a)]; toxicological footprint [Fig. 1(b)]; eco-indicator 99 [Fig. 1(c)]; input-output (IO) upstream greenhouse gas (GHG) emissions [Fig. 1(d)]. For detailed analysis of how the results were derived, we refer readers to the original research article. ${ }^{[10]}$ From Fig. 1, KNN produces a significantly higher environmental effect across all the categories of impact considered. Further, in contrast to PZT, the environmental impact and pollution associated with $\mathrm{KNN}$ is found to be located at the earlier stages of its life cycle (involving extraction and purification processes), where it generates a far greater environmental burden than PZT. For a more detailed analysis of the data, we refer the reader to supplementary information for Ref. 10.

Figure 1(a) focuses on primary energy consumption during the fabrication activities (i.e., drying, calcination and sintering). KNN consumes more thermal and electrical energy across the major fabrication activities except in milling where it consumes approximately the same as PZT. The technical justification for the wide disparity in energy consumption, between $\mathrm{KNN}$ and PZT, seen in Fig. 1(a) relates to its specific heat capacity, which is notably higher than that of PZT. This drives up KNN's primary energy demand as it consumes higher thermal energy during the heating cycles involved in its fabrication. Furthermore, niobium pentoxide, $99.53 \%$ of the material 


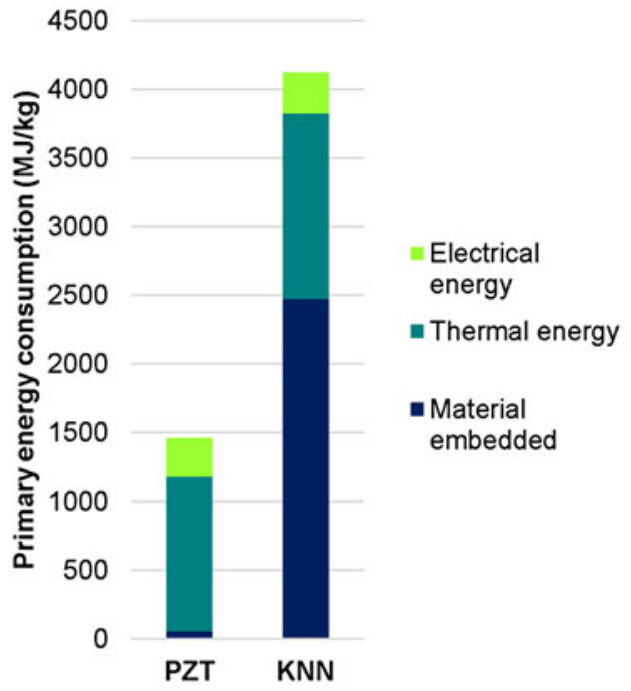

(a) Primary energy consumption

25

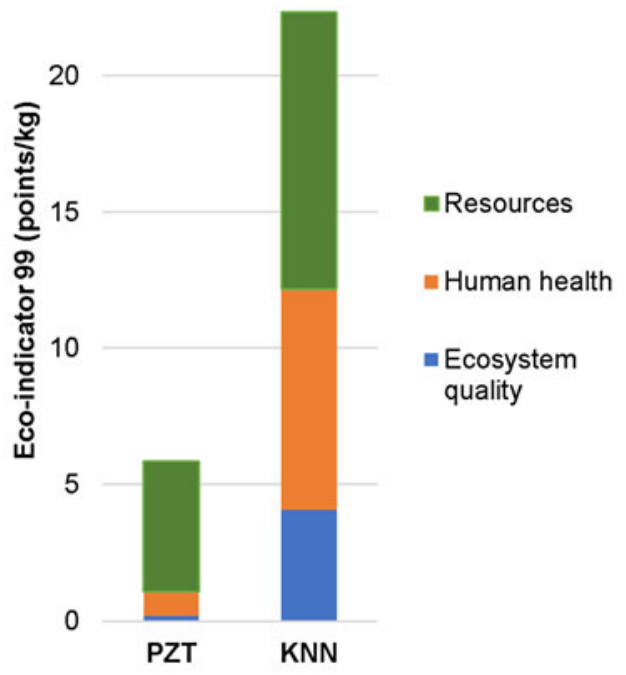

(c) Eco-indicator comparison

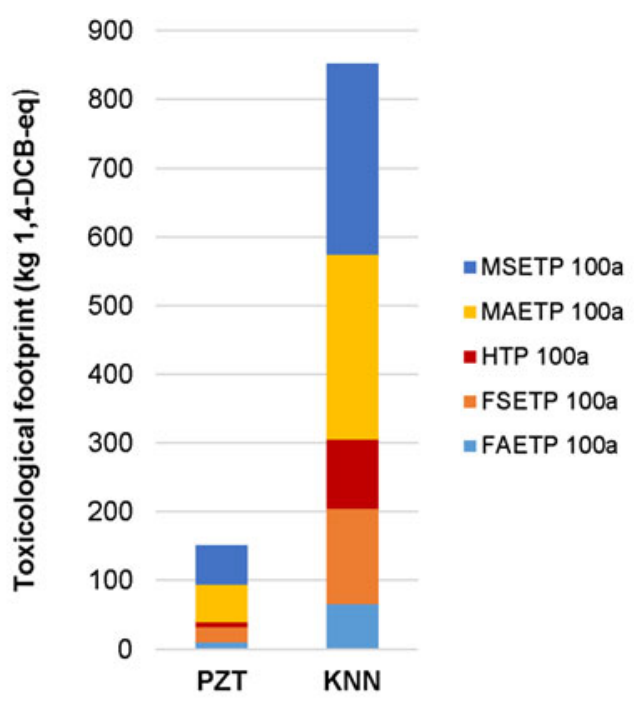

(b) Toxicological footprint

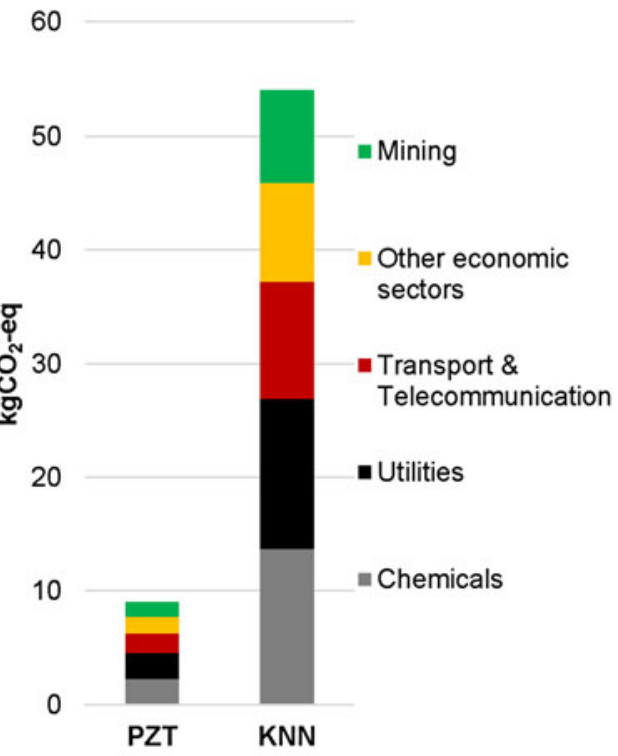

(d) IO upstream GHG comparison

Figure 1. Comparison of PZT versus KNN. (a) Primary energy demand, (b) toxicological footprint, (c) eco-indicator 99, (d) I0 upstream GHG emissions. (a) Primary energy consumption (b) Toxicological footprint. (c) Eco-indicator comparison. (d) IO upstream GHG comparison.

impact category, has the highest embodied carbon footprint of all the oxide raw materials. ${ }^{[28-30]}$

Figure 1(b) concentrates on the toxicological footprint. Our assessment of the toxicological footprint involves: freshwater aquatic ecotoxicity (FAETP 100a), freshwater sediment ecotoxicity (FAETP 100a), human toxicity (HTP 100a), marine aquatic ecotoxicity (MAETP 100a), and marine sediment ecotoxicity (MSETP 100a). Figure 1(b) reveals an alarmingly high toxicological footprint of KNN when compared with PZT. The main culprit again, for $\mathrm{KNN}$, is niobium pentoxide which constitute $85 \%, 85 \%, 79 \%, 93 \%$, and $79 \%$ of the respective impact category. Essentially, in terms of the damage to ecosystem quality, resources, and human health, the production of KNN outweighs that of PZT as shown in Fig. 1(c), whereas Fig. 1 (d) highlights KNN's detrimental effect on key economic sectors based on the upstream IO GHG emissions.

Mining and production of KNN through its major constituent $\left(\mathrm{Nb}_{2} \mathrm{O}_{5}\right)$ therefore have a high cost to the environment with the release of harmful waste. The harmful waste associated with niobium production includes heavy and radioactive metals, leaching of acid, the improper dispersion, which perniciously impinges upon air quality, groundwater, and ecological land 
resources. ${ }^{[30-32]}$ Essentially, the environmental impact of KNN is shifted to the early phase of its life cycle, far before it gets passed to manufacturers of high-end consumer products. Salvaging the "green" reputation of KNN therefore, requires tighter environmental legislation and controls surrounding the mining and extraction of $\mathrm{Nb}_{2} \mathrm{O}_{5}$.

\section{Extraction phase of $\mathrm{Nb}_{2} \mathrm{O}_{5}$ and potential remedial action}

Figure 2 presents and illustrates the four key stages involved in the extraction and processing of niobium. At each stage, the figure shows the startling impact on air quality, surface and groundwater quality and the land. Some of the stages are, however, more environmentally deleterious than others. For instance, the mining and production of niobium result in toxic discharges into the environment, which include: arsenic, nitrates, antimony, and sulfides. These substances precipitate toxicity, eutrophication, and acidification that constitute threats to aquatic life. Moreover, the release of radon gas into the atmosphere affects air quality ${ }^{[32]}$; the deterioration in landform during excavation, instigates sterilization of soil resources as a result of open pit waste rock dump; soil contamination occurs through leakage of hazardous chemicals ${ }^{[30-32]}$; and the ferricrete layer of soil is impaired during excavation. In addition to the above concerns, some other issues stemming from the extraction of $\mathrm{Nb}_{2} \mathrm{O}_{5}$ pertains to biodiversity (e.g., damage to sensitive habitats and increased pressure on ecological resources); cultural heritage (e.g., disturbance of archaeological and cultural sites during site clearance and excavations); visuals (e.g., disturbance of line of sight); socio-economics (e.g., resettlement of members of the community and reduced access to land for agriculture and fuel collection); and noise (e.g., disturbance of noise receptors during day and night due to movement of machinery and vehicles and mechanical operation of plant components).

To minimize the above impacts, several steps are required. First, the impact of land use during the extraction of $\mathrm{Nb}_{2} \mathrm{O}_{5}$, could be reduced by stripping and stockpiling of utilizable soil before the extraction process begins. ${ }^{[32]}$ Second, the quantitative tool of dispersion modeling can be used to minimize air quality disturbance. The results from such modeling could help project the potential volume of dust associated with the process and mitigation strategies such as installation of wet suppression at key sources and surfacing of roads with chemical dust suppressants could therefore be implemented. Third, to minimize the effects of soil/river contamination and erosion of soil resources, dams constructed should be deconstructed at the end of life of the mining operation to restore original landform. ${ }^{[10]}$ Fourth, all ancillary effluents should be contained and treated prior to release and hazardous waste should be stored and handled in leak-proof facilities to prevent spillage. Moreover, disposal of waste should be conducted offsite at available facilities until such a period when general and hazardous waste sites are developed.

Beyond this, we propose that stringent environmental regulations should be attached to mining permissions for the
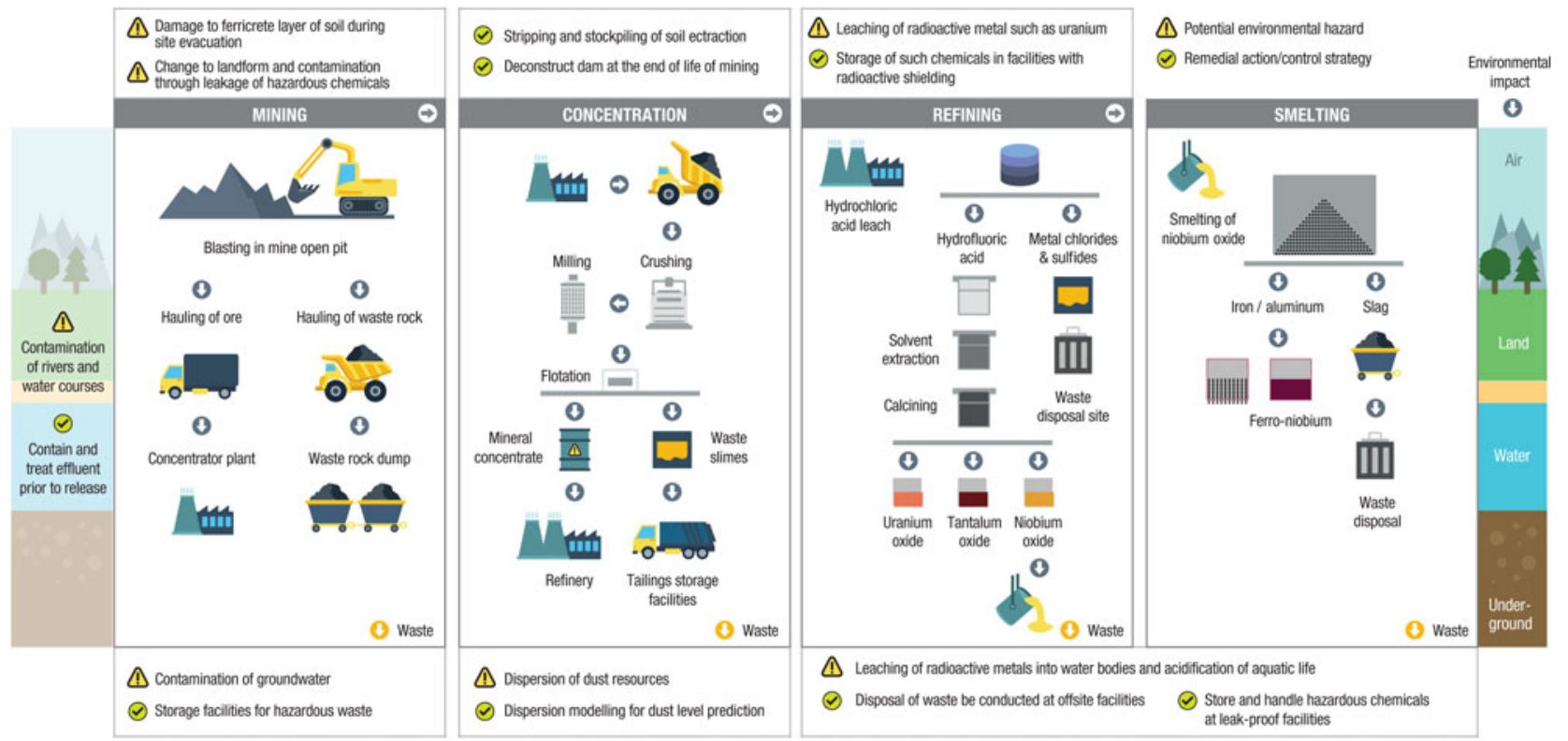

Figure 2. Concise schematic representation of the extraction of niobium from its ore, indicating the most important hazards (denoted by danger icon) causing significant adverse effect on air quality, water quality and the land and potential remedial action/strategies for their control (denoted by solution icon), derived from Refs. 28-32. Typically, the ore is crushed and milled and subjected to flotation to form a pyrochlore concentrate. The concentrate, which include acid-leaching (e.g., hydrochloric acid, sulfuric acid and hydrofluoric acid) and solvent extraction are treated to form niobium oxide, which is further processed to obtain the targeted form of niobium. By-products such as tantalum oxide and uranium oxide may be generated and can be sold commercially. 
extraction of niobium from its ore. We also encourage private sector-led initiatives involving the use of innovative technology and methods for control of emission resulting from the extraction of niobium. A good number of these approaches have been expounded in Ref. 10.

\section{Health hazards of PZT}

Whilst the authors of Ref. 10 point out a number of observations to unmask the environmental impact of KNN at the early stage of its life cycle, the analysis does not detract from the toxicity of PZT based on its high $\mathrm{PbO}$ concentration. Indeed, the ecotoxicity impact category recognizes that $\mathrm{PbO}$ contributes $6 \%, 8 \%, 8 \%, 12 \%$, and $7 \%$ to the negative effect of PZT on marine aquatic ecotoxicity, freshwater sediment ecotoxicity, freshwater aquatic ecotoxicity, human toxicity, and terrestrial ecotoxicity, respectively. $\mathrm{Pb}$ poisoning (e.g., muscle and bone fatigue, aches in muscles and joints, abdominal discomfort, slowing down of intellectual and neurological growth, etc.) is already well-reported elsewhere. ${ }^{[33,34]}$ The authors also note that $\mathrm{PbO}$ contributes to acidification (7\%), eutrophication (5\%), land use (6\%), and malodors air (38\%). Pb-based chemicals can also prompt damage to essential body organs such as kidney, liver, and the nervous tissues. ${ }^{[35]}$ Given these dangers, there is a legitimate concern about the presence of $\mathrm{Pb}$ in PZT, and all paths to the leakage and exposure associated with its fabrication stages should be handled with extreme caution. Thus, while acknowledging the advantages of PZT over $\mathrm{KNN}$ in terms of production cost (lower), processing energy (well-established), and overall pollution (less), the $\mathrm{Pb}$ content violates the requirement of some applications and smart devices. This in turn makes PZT incompatible with implantable bio-micro-electro-mechanical systems (bio-MEMS) as well as in in vivo piezoelectric sensors. ${ }^{[36]}$ In contrast, $\mathrm{Pb}$-free piezoelectric materials such as KNN have great potential in biologic applications.

\section{LCA of PZT versus KNN functional materials - a conundrum}

We envisage that the outcomes of this analysis will force the material science community to confront an uncomfortable fact: that a $\mathrm{Pb}$-free replacement for a $\mathrm{Pb}$-based piezoelectric material may not in fact be truly "green" when considered holistically on a much larger scale than the laboratory. This leaves us with the conundrum, schematically illustrated in Fig. 3: "what is more acceptable to the stakeholders and policy makers: the continued use of a PZT with its superior piezoelectric performance but its well-established toxicity in the use phase or the less-toxic KNN, with inferior properties, higher production costs combined with major environmental concerns during mining and extraction?"

The answer to this conundrum must be based on different factors, some of which, though not mutually exclusive, impose constraint on the techno-economic possibilities that surround functional material substitution in advanced applications. Hence, the debate over the replacement of PZT with KNN will not be driven purely by environmental consideration, but by the context in which the decision is to take place.

\section{Conclusion and future outlook}

Through comprehensive comparative LCA, the environmental credentials of KNN and PZT were scrutinized over a wide range of indicators not previously considered in the literature.
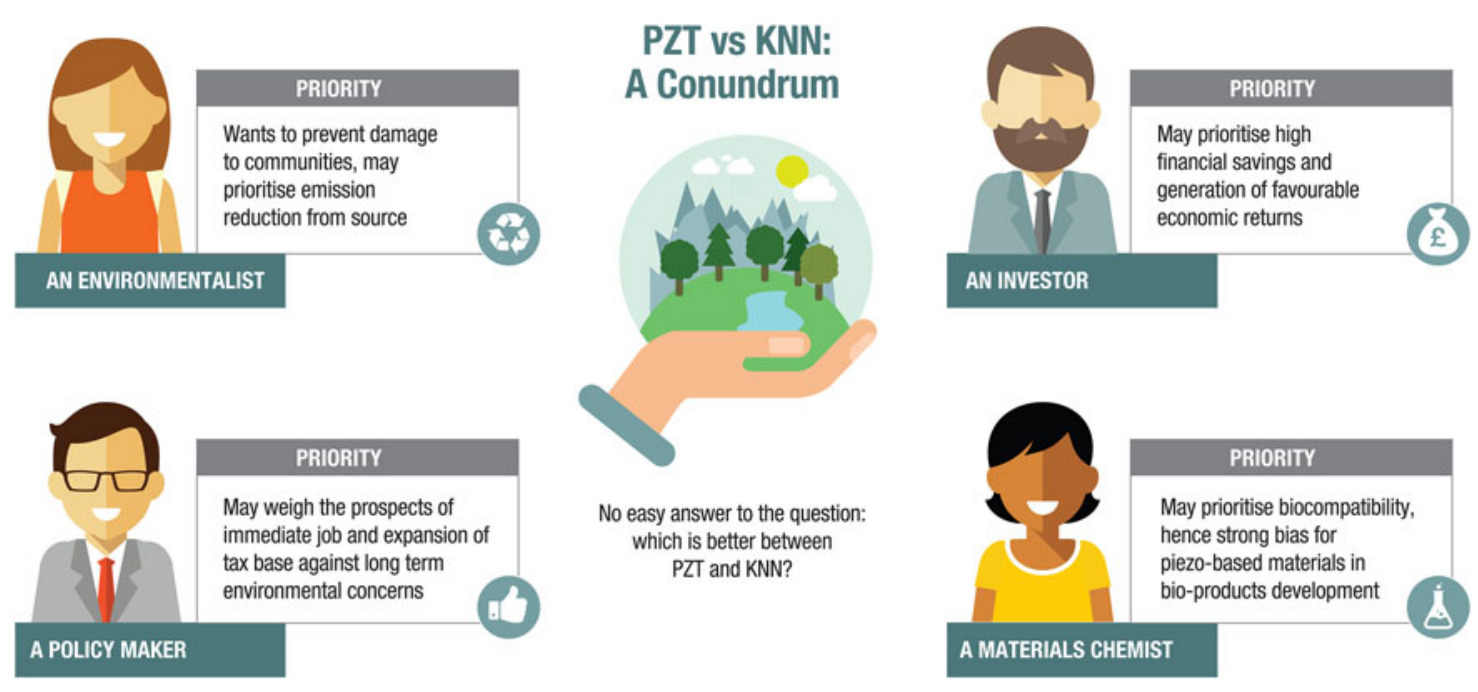

Figure 3. Pictorial representation of the conundrum presented through the LCA of KNN versus PZT. It illustrates the fictitious perspectives of four different stakeholders. It is possible that an investor may prioritize high financial savings along with gainful economic return from the development of KNN-based products, while an environmentalist sees emission reduction from material sourcing as urgent. In the eyes of a materials chemist, whose research interest is aligned with the design of implantable piezo-based products, biocompatibility may be a top priority. Yet, through the prism of a policy maker in a struggling economy, a short-term option of creating new local jobs and expanding the tax base may be favored against the long term environmental concerns. 
This revealed a shift of the environmental impact of KNN to the earlier stages of its life cycle, where it causes greater environmental damage than PZT. Without downplaying the hazardous effect of the $\mathrm{Pb}$ content of PZT, the findings identify $\mathrm{Nb}_{2} \mathrm{O}_{5}$ in $\mathrm{KNN}$ to be responsible for its greater environmental impact across all the 16 categories considered.

The methodological framework put forth in our study focused on KNN, but we posit that the idea holds great potential to assess the environmental profile of other emerging materials and technologies at the early stages before expensive investments and resources are committed. Overall, this work highlights the importance of considering inclusive LCA and environmental profile assessment among the core principles of material substitution and optimization before pinning the label of "green" or "environmentally friendly" on any material, product or process. Finally, and crucially, given that the recent review of RoHS exemptions allows only a 3-year window on $\mathrm{Pb}$-based piezoelectric materials, the reported findings of this research has practical implications for future RoHS legislation concerning the development and applications of piezoelectric materials within the European Union and worldwide. It is our hope that this work further sparks the drive for a multi-pronged approach to the challenges of sustainable functional material.

\section{Acknowledgments}

This work was financially supported by the Engineering and Physical Sciences Research Council (Grant no. EP/L017563/ 1) through the University of Sheffield under the project titled: Substitution and Sustainability in Functional Materials and Devices.

\section{References}

1. J. Koruza, B. Rožič, G. Cordoyiannis, B. Malič, and Z. Kutnjak: Large electrocaloric effect in lead-free $\mathrm{K}_{0.5} \mathrm{Na}_{0.5} \mathrm{NbO}_{3}-\mathrm{SrTiO}_{3}$ ceramics. Appl. Phys. Lett. 106, 202905 (2015).

2. H. Zhang, C. Chen, X. Zhao, H. Deng, B. Ren, X. Li, H. Luo, and S. Li: Structure and electrical properties of $\mathrm{Na}_{1 / 2} \mathrm{Bi}_{1 / 2} \mathrm{TiO}_{3-x} \mathrm{~K}_{1 / 2} \mathrm{Bi}_{1 / 2} \mathrm{TiO}_{3}$ leadfree ferroelectric single crystals. Solid State Commun. 201, 125 (2015).

3. T. Lusiola, F. Bortolani, Q. Zhang, and R. Dorey: Molten hydroxide synthesis as an alternative to molten salt synthesis for producing $\mathrm{K}_{0.5} \mathrm{Na}_{0.5} \mathrm{NbO}_{3}$ lead free ceramics. J. Mater. Sci. 47, 1938 (2012).

4. Y. Saito, H. Takao, T. Tani, T. Nonoyama, K. Takatori, T. Homma, T. Nagaya, and M. Nakamura: Lead-free piezoceramics. Nature 432, 84 (2004).

5. A. Nourmohammadi, M. Bahrevar, S. Schulze, and M. Hietschold: Electrodeposition of lead zirconate titanate nanotubes. J. Mater. Sci. 43, 4753 (2008)

6. C. He, X. Li, Z. Wang, Y. Liu, D. Shen, T. Li, X. Long, and Z.-G. Ye: Growth of $\mathrm{Pb}\left(\mathrm{Fe}_{1 / 2} \mathrm{Nb}_{1 / 2}\right) \mathrm{O}_{3}-\mathrm{Pb}\left(\mathrm{Yb}_{1 / 2} \mathrm{Nb}_{1 / 2}\right) \mathrm{O}_{3}-\mathrm{PbTiO}_{3}$ piezo-/ferroelectric crystals for high power and high temperature applications. CrystEngComm 14, 4407 (2012).

7. F. Cucchiella, I. D'Adamo, S.L. Koh, and P. Rosa: Recycling of WEEEs: an economic assessment of present and future e-waste streams. Renew. Sustain. Energy Rev. 51, 263 (2015).

8. S. Koh, T. Ibn-Mohammed, A. Acquaye, K. Feng, I. Reaney, K. Hubacek, H. Fujii, and K. Khatab: Drivers of US toxicological footprints trajectory 1998-2013. Sci. Rep. 6, 39514 (2016).

9. M. Kutz: Mechanical Engineers' Handbook, Materials and Engineering Mechanics (John Wiley \& Sons, West Sussex, England, 2015).
10. T. Ibn-Mohammed, S. Koh, I. Reaney, A. Acquaye, D. Wang, S. Taylor, and A. Genovese: Integrated hybrid life cycle assessment and supply chain environmental profile evaluations of lead-based (lead zirconate titanate) versus lead-free (potassium sodium niobate) piezoelectric ceramics. Energy Environ. Sci. 9, 3495 (2016).

11.P. Curie and J. Curie: Développement, par pression, de l'électricité polaire dans les cristaux hémièdres à faces inclinées. C. R. Acad. Sci. 91, 294 (1880).

12. R. Jaeger and L. Egerton: Hot pressing of potassium-sodium niobates. J. Am. Ceram. Soc. 45, 209 (1962).

13.W. Heywang, K. Lubitz, and W. Wersing: Piezoelectricity: Evolution and Future of a Technology (Springer Science \& Business Media, Berlin/Heidelberg, 2008).

14. W. Jo, R. Dittmer, M. Acosta, J. Zang, C. Groh, E. Sapper, K. Wang, and J. Rödel: Giant electric-field-induced strains in lead-free ceramics for actuator applications-status and perspective. J. Electroceram. 29, 71 (2012).

15. J. Rödel, W. Jo, K.T. Seifert, E.M. Anton, T. Granzow, and D. Damjanovic: Perspective on the development of lead-free piezoceramics. J. Am. Ceram. Soc. 92, 1153 (2009).

16. H. Ledbetter, H. Ogi, and N. Nakamura: Elastic, anelastic, piezoelectric coefficients of monocrystal lithium niobate. Mech. Mater. 36, 941 (2004).

17. T. Karaki, M. Adachi, and K. Yan: High-performance lead-free barium titanate piezoelectric ceramics. In Advances in Science and Technology, Vol. 54, edited by P. Vincenzini and G. D'arrigo (Trans Tech Publ, Zurich, Switzerland, 2008), pp. 7-12.

18. H. Takahashi, Y. Numamoto, J. Tani, K. Matsuta, J. Qiu, and $\mathrm{S}$. Tsurekawa: Lead-free barium titanate ceramics with large piezoelectric constant fabricated by microwave sintering. Japan. J. Appl. Phys. 45, L30 (2006).

19. K.-I. Kakimoto, T. Yoshifuji, and H. Ohsato: Densification of tungstenbronze $\mathrm{KBa}_{2} \mathrm{Nb}_{5} \mathrm{O}_{15}$ lead-free piezoceramics. J. Eur. Ceram. Soc. 27, 4111 (2007).

20. P. Panda and B. Sahoo: PZT to lead free piezo ceramics: a review. Ferroelectrics 474, 128 (2015).

21.J.-F. Li, K. Wang, F.-Y. Zhu, L.-Q. Cheng, and F.-Z. Yao: (K, Na) $\mathrm{NbO}_{3}{ }^{-}$ based lead-free piezoceramics: fundamental aspects, processing technologies, and remaining challenges. J. Am. Ceram. Soc. 96, 3677 (2013).

22. S. Xu and J.F. Li: Synthesis and piezoelectricity of single-crystalline (K, $\mathrm{Na} \mathrm{NbO}_{3}$ nanobars. J. Am. Ceram. Soc. 94, 3812 (2011).

23. L.-Q. Cheng, K. Wang, and J.-F. Li: Synthesis of highly piezoelectric leadfree $(\mathrm{K}, \mathrm{Na}) \mathrm{NbO}_{3}$ one-dimensional perovskite nanostructures. Chem. Commun. 49, 4003 (2013).

24. H. Ge, Y. Hou, M. Zhu, H. Wang, and H. Yan: Facile synthesis and high d 33 of single-crystalline $\mathrm{KNbO}_{3}$ nanocubes. Chem. Commun. 41, 5137 (2008).

25. T. Ibn-Mohammed, R. Greenough, S. Taylor, L. Ozawa-Meida, and A. Acquaye: Operational vs. embodied emissions in buildings-a review of current trends. Energy Build. 66, 232 (2013).

26. S. Hellweg and L. Milà i Canals: Emerging approaches, challenges and opportunities in life cycle assessment. Science 344,1109 (2014).

27. T. Ibn-Mohammed, R. Greenough, S. Taylor, L. Ozawa-Meida, and A. Acquaye: Integrating economic considerations with operational and embodied emissions into a decision support system for the optimal ranking of building retrofit options. Build. Environ. 72, 82 (2014).

28. R. Linnen, D.L. Trueman, and R. Burt: Tantalum and niobium. In Critical Metals Handbook, edited by G. Gunn (John Wiley \& Sons, Oxford, 2014), ch. 15.

29. D.A. Mackay and G.J. Simandl: Geology, market and supply chain of niobium and tantalum -a review. Mineral. Deposit. 49, 1025 (2014).

30. British Geological Survey: Niobium-Tantalum: definition, mineralogy and deposits (2015). Available from: http://nora.nerc.ac.uk/14327/1/ comm_profile_niobium_tantalum\%5B1\%5D.pdf (accessed November 20, 2016).

31. Globe Metals \& Mining: Environmental scoping report and terms reference for environmental impact assessment (2011). Available from: http://www.globemetalsandmining.com.au/Files/Projects/Kanyika/ Environmental-Scoping-Report.aspx (accessed November 20, 2016). 
32. Globe Metals \& Mining: Environmental impact assessment report for the Kanyika niobium project (2012). Available from: http://www.globemetalsandmining.com.au/Files/Projects/Kanyika/enironmental-reports/S0522KANYIKA-PROJECT-EIA-REPORT-FINAL_REVISION_01.aspx (accessed November 20, 2016).

33. M.D. Maeder, D. Damjanovic, and N. Setter: Lead free piezoelectric materials. J. Electroceram. 13, 385 (2004).

34.D. Barltrop and A.M. Smith: Kinetics of lead interaction with human erythrocytes. Postgrad. Med. J. 51, 770 (1975).

35. A. Babayigit, A. Ethirajan, M. Muller, and B. Conings: Toxicity of organometal halide perovskite solar cells. Nat. Mater. 15, 247 (2016).

36. S.H. Lee, C.K. Jeong, G.-T. Hwang, and K.J. Lee: Self-powered flexible inorganic electronic system. Nano Energy 14, 111 (2015). 